\title{
A meta-analysis of the relationship between vitamin D receptor gene Apal polymorphisms and polycystic ovary syndrome
}

\author{
Fang Liang ${ }^{1, A, B, D, E}$, Na Ren ${ }^{2, A, D, E}$, Hongxia Zhang ${ }^{1, C}$, Jian Zhang ${ }^{1, E}$, Qingguo Wu ${ }^{1, D}$, \\ Rui Song ${ }^{1, B}$, Zhenfeng Shi ${ }^{1, E}$, Zhanxiu Zhang ${ }^{3, B}$, Kuixiang Wang ${ }^{3, B, E, F}$ \\ 1 Departments of Endocrinology, Xingtai People's Hospital, Hebei Medical University, China \\ ${ }^{2}$ Departments of Endocrinology, $3^{\text {rd }}$ Xiangya Hospital of Central South University, Changsha, China \\ ${ }^{3}$ Departments of Joint Orthopedics, Xingtai People's Hospital, Hebei Medical University, China \\ A - research concept and design; $B$ - collection and/or assembly of data; $C$ - data analysis and interpretation; \\ $D$ - writing the article; $E$ - critical revision of the article; $F$ - final approval of the article
}

Address for correspondence

Kuixiang Wang

E-mail: kxe721@163.com

Funding sources

None declared

Conflict of interest

None declared

Received on August 10, 2017

Reviewed on October 27, 2017

Accepted on February 28, 2018

Published online on December 20, 2018

Cite as

Liang $\mathrm{F}$, Ren N, Zhang H, et al. A meta-analysis of the relationship between vitamin D receptor gene Apal polymorphisms and polycystic ovary syndrome. Adv Clin Exp Med. 2019;28(2):255-262. doi:10.17219/acem/85882

DOI

10.17219/acem/85882

Copyright

Copyright by Author(s)

This is an article distributed under the terms of the

Creative Commons Attribution Non-Commercial License

(http://creativecommons.org/licenses/by-nc-nd/4.0/)

\section{Abstract}

Background. Emerging evidence from pre-clinical and clinical studies has shown that vitamin D (VD) plays an important role in the pathogenesis of polycystic ovary syndrome (PCOS). Potentially functional Apal polymorphism of vitamin D receptor (VDR) gene has been implicated in PCOS risk, but individually published studies have yielded inconclusive results.

Objectives. Studies on the associations of VDR gene polymorphisms with PCOS susceptibility reported conflicting results. The objective of this study was to perform a systematic meta-analysis to clarify this issue.

Material and methods. We searched for all publications regarding the associations mentioned above in PubMed, Web of Science, Embase, and China National Knowledge Infrastructure (CNKI) databases updated up to April 2017. A meta-analysis of the overall odds ratios (ORs) with 95\% confidence interval (CI) was calculated with the fixed or random effect model.

Results. A total of 7 studies fulfilling the inclusion criteria were included in this meta-analysis (1,350 cases and 960 controls). Pooled ORs showed a significant association between Apal polymorphism and PCOS risk in all 4 genetic models. Subgroup analysis by ethnicity showed that Apal polymorphism was associated with the risk of PCOS in Asians (aa vs AA: $0 R=1.54,95 \%(\mathrm{Cl}=1.04-2.28, \mathrm{p}=0.03$ ). However, Apal polymorphism (a vs $A: O R=1.34,95 \% C l=1.00-1.79, p=0.02 ; a d+A a$ vs $A A: O R=1.36,95 \% C l=1.04-1.79, p=0.03$ ) was associated with the risk of PCOS in Caucasians.

Conclusions. Our meta-analysis demonstrated that PCOS risk was significantly associated with VDR gene Apal polymorphism. However, due to the relatively small sample size in this meta-analysis, further studies with a larger sample size should be conducted to confirm the findings.

Key words: meta-analysis, polycystic ovary syndrome, vitamin D receptor, genetic polymorphisms, Apal 


\section{Introduction}

Polycystic ovary syndrome (PCOS) is a common multifaceted metabolic disease with a strong genetic component in women of fertile age. ${ }^{1}$ The PCOS incidence increased and ranges from $5 \%$ to $10 \%$, with the age of affected females ranging from 12 years to 45 years. ${ }^{2-4}$ Being a complex multigenic and heteroplasmy disease, PCOS results in several disorders, such as infertility, ${ }^{5}$ myocardial infarction, ${ }^{6}$ dysfunctional uterine bleeding, ${ }^{7}$ cardiovascular risk, ${ }^{8}$ endometrial carcinoma, ${ }^{9}$ insulin resistance (IR), ${ }^{10}$ diabetes mellitus, ${ }^{10}$ hyperandrogenism (hirsutism, acne, male pattern hair loss), ${ }^{11}$ oligoanovulation and polycystic ovaries, dyslipidemia, amenorrhea, and hypertension, as well is associated with obesity and high levels of cholesterol. ${ }^{12}$

As a secosteroid hormone, vitamin D (VD) is acquired and synthesized from the diet and ultraviolet radiation. ${ }^{13}$ Besides its calciotropic function, VD has potent non-classical properties, including immunomodulatory, anti-inflammatory, antioxidant, antiangiogenic, and antiproliferative properties. ${ }^{14}$ It is well-known that the interaction of VD with target tissues is mediated by the VD receptor, a member of the steroid/thyroid hormone receptor family with the function of a transcriptional activator of many genes. There is accumulating evidence suggesting that the VD endocrine system is involved in a wide variety of biological processes, including IR and type 2 diabetes mellitus. ${ }^{10}$ Insulin resistance, which is commonly present in women with PCOS, may play an important role in the long-term complications of PCOS. ${ }^{15}$ Accumulating evidence suggests that VD deficiency might be a causal factor in the pathogenesis of IR and the metabolic syndrome in PCOS. ${ }^{16}$ The VDR gene is located on chromosome 12q13.1, consists of 11 exons and has an extensive promoter region capable of generating multiple tissue-specific transcripts. There are 4 single-nucleotide polymorphisms (SNPs) in the VDR gene, FokI (rs10735810), BsmI (rs1544410), ApaI (rs7975232), and TaqI (rs731236), which have been studied most frequently. ${ }^{17}$ Moreover, previous studies have revealed significant associations between VDR gene polymorphisms and PCOS. ${ }^{18-20}$

Considering the past establishment of the important functions of $V D R$ gene ApaI polymorphism, many studies have explored the association between $V D R$ gene ApaI polymorphism and PCOS risk. ${ }^{20-26}$ However, individual studies yielded inconsistent and even conflicting results. This may be attributed to limited sample sizes and inadequate statistical power, which might affect their reliability. A meta-analysis is a statistical procedure of pooling the data from individual studies, increasing effective sample size, enhancing statistical power of the analysis, and producing a single estimate of an effect. Therefore, we performed a comprehensive meta-analysis to further evaluate the association of VDR gene ApaI (rs7975232) polymorphism and PCOS.

\section{Material and methods}

\section{Literature search}

Eligible studies were systematically searched in PubMed, Web of Science, Embase, and China National Knowledge Infrastructure (CNKI) databases up to April 2017, with keywords including: [PCOS OR Polycystic Ovary Syndrome] and [VDR ApaI OR VD receptor ApaI] and [polymorphism OR mutation OR variation OR SNP]. All studies that showed potential relevance of genetic association were assessed by examining their titles and abstracts. All published studies matching the abovementioned eligibility criteria were obtained and tested for their eligibility for incorporation in the present meta-analysis (Fig. 1).

\section{Inclusion and exclusion criteria}

Studies were chosen if they met the following criteria: 1) published studies; 2) evaluated association between VDR gene ApaI polymorphism and PCOS risk; 3) a casecontrol or cohort study based on unrelated individuals; 4) sufficient data for examining odds ratios (ORs) with 95\% confidence interval (CI); and 5) genotype distributions of polymorphism of the control population consistent with Hardy-Weinberg equilibrium (HWE). The most recent article was used to extract data if the authors published more than 1 article with the same study data. Case reports, editorials, reviews, abstracts from conferences, republished or duplicate studies, and studies with insufficient information on data extraction were excluded.

\section{Data extraction and quality assessment}

The following information was extracted independently by 2 authors from each study: 1) name of the $1^{\text {st }}$ author; 2) year of publication; 3) country of origin; 4) ethnicity of the study population; 5) genotype distribution or allele frequencies; and 6) sample sizes of cases and controls, and the SNPs included (Table 1). The 2 authors independently assessed the articles for compliance with the inclusion/exclusion criteria, resolved disagreements and reached a consistent decision.

\section{Statistical analysis}

Review Manager v. 5.3 software (Cochrane Collaboration, Oxford, UK) was used for all statistical analyses. Genotype frequency was assessed by the $X^{2}$ test in the control group for HWE. The strength of the association between VDR gene ApaI polymorphism and PCOS susceptibility was assessed by calculating the pooled ORs and 95\% CI of the Z-test. ApaI genetic models were used for analyses: allelic model, common model, risk model, and additive model; the p-values were corrected for multiple testing using the false discovery rate. $\mathrm{I}^{2}$ statistic were used to test 
Table 1. Characteristics of experimental methods in the 7 studies included in the meta-analysis

\begin{tabular}{|c|c|c|c|c|}
\hline Author (publication year) & Case selection & Control selection & Genotyping method & NOS score \\
\hline Mahmoudi et al. (2009)24 & $\mathrm{NIH}$ criteria & normal healthy women & PCR-RFLP & 6 \\
\hline El-Shal et al. $(2013)^{23}$ & Rotterdam criteria & normal healthy women & PCR-RFLP & 7 \\
\hline Dasgupta et al. $(2015)^{22}$ & Rotterdam criteria & normal healthy women & PCR-RFLP & 5 \\
\hline Wehr et al. $(2011)^{19}$ & Rotterdam criteria & normal healthy women & genotyping assay & 8 \\
\hline Huabin et al. $(2016)^{26}$ & Rotterdam criteria & $\begin{array}{l}\text { a contemporaneous hospitalized } \\
\text { woman with benign ovarian tumors }\end{array}$ & PCR-RFLP & 5 \\
\hline Mahmoudi et al. $(2015)^{21}$ & $\mathrm{NIH}$ criteria & normal healthy women & PCR-RFLP & 5 \\
\hline Jędrzejuk et al. (2015)20 & Rotterdam criteria & normal healthy women & PCR-RFLP & 7 \\
\hline
\end{tabular}

$\mathrm{NIH}$ - National Institutes of Health; NOS - Newcastle-Ottawa Scale; PCR-RFLP - polymerase chain reaction - restriction fragments length polymorphism.

the heterogeneity among studies, and studies with $\mathrm{I}^{2}<50 \%$ were considered to be of low heterogeneity. Publication bias was assessed by funnel plot. A p-value $<0.05$ was considered significant for all tests.

\section{Results}

\section{Characteristics of the studies}

A comprehensive flowchart of the selection process of the studies is shown in Fig. 1. Our initial search of the literature yielded 161 publications. After reading the titles and abstracts, 21 potential studies were included for full-text view. After reading full texts, 4 studies were excluded for not reporting usable data. Finally, a to-

Table 2. Characteristics of experimental groups in the 7 studies included in the meta-analysis

\begin{tabular}{|c|c|c|c|c|}
\hline Author (publication year) & Region & Latitude & Ethnicity & Age (case/control) \\
\hline Mahmoudi et al. (2009)24 & Tehran, Iran & $36^{\circ} \mathrm{N}$ & Asian & $19-42 / 18-54$ \\
\hline El-Shal et al. $(2013)^{23}$ & Zagazig, Egypt & $30^{\circ} \mathrm{N}$ & Caucasian & $29.8 \pm 5.6 / 29.3 \pm 6.2$ \\
\hline Dasgupta et al. $(2015)^{22}$ & Hyderabad, India & $18^{\circ} \mathrm{N}$ & Asian & no mention \\
\hline Wehr et al. $(2011)^{19}$ & Graz, Austria & $47^{\circ} \mathrm{N}$ & Caucasian & $23-31 / 26-36$ \\
\hline Huabin et al. $(2016)^{26}$ & Jiangxi, China & $28^{\circ} \mathrm{N}$ & Asian & $22.56 \pm 4.56 / 23.14 \pm 3.21$ \\
\hline Mahmoudi et al. $(2015)^{21}$ & Tehran, Iran & $36^{\circ} \mathrm{N}$ & Asian & $19-42 / 19-44$ \\
\hline Jędrzejuk et al. $(2015)^{20}$ & Lower Silesia, Poland & $50^{\circ} \mathrm{N}$ & Caucasian & $20-35$ \\
\hline
\end{tabular}

Table 3. Genotype frequencies of VDR Apal polymorphisms in 7 studies included

\begin{tabular}{|c|c|c|c|c|c|}
\hline \multirow{2}{*}{$\begin{array}{c}\text { Author } \\
\text { (publication year) }\end{array}$} & \multicolumn{2}{|c|}{ Genotype frequency (AA/Aa/aa/total) } & \multicolumn{2}{|c|}{ Allele-wise frequency (A/a) } & \multirow{2}{*}{$\begin{array}{c}\text { HWE } \\
\text { (p-value) }\end{array}$} \\
\hline & case & control & case & control & \\
\hline Mahmoudi et al. (2009)24 & $58 / 68 / 36 / 16$ & $49 / 90 / 23 / 162$ & $184 / 140$ & $188 / 136$ & NS \\
\hline El-Shal et al. $(2013)^{23}$ & $63 / 65 / 22 / 150$ & $68 / 64 / 18 / 150$ & $191 / 109$ & $200 / 100$ & 0.800 \\
\hline Dasgupta et al. $(2015)^{22}$ & $12 / 120 / 118 / 250$ & $12 / 117 / 121 / 250$ & $144 / 356$ & $141 / 359$ & 0.014 \\
\hline Wehr et al. $(2011)^{19}$ & $142 / 274 / 127 / 543$ & $48 / 60 / 37 / 145$ & $558 / 528$ & $156 / 134$ & 0.155 \\
\hline Huabin et al. $(2016)^{26}$ & $22 / 58 / 40 / 120$ & $39 / 55 / 26 / 120$ & $102 / 138$ & $133 / 107$ & 0.021 \\
\hline Mahmoudi et al. $(2015)^{21}$ & $8 / 21 / 6 / 35$ & $15 / 11 / 9 / 35$ & $37 / 33$ & $41 / 29$ & 0.054 \\
\hline Jędrzejuk et al. (2015)20 & 19/52/19/90 & $32 / 49 / 17 / 98$ & $90 / 90$ & $113 / 83$ & 0.204 \\
\hline
\end{tabular}

NS - not significant; HWE - Hardy-Weinberg equilibrium.

tal of 7 case-control studies in 7 articles were identified and met our inclusion criteria, encompassing 1,350 PCOS patients and 960 controls in total. The main characteristics of these selected studies were summarized in Table 1, Table 2 and Table 3, including $1^{\text {st }}$ author, publication year, country of origin, ethnicity of the study group, genotype distribution, and HWE. Generally, most of the studies (>80\%) scored 5 stars or more in the Newcastle-Ottawa scale (NOS), and indicated modest to decent quality (Table 1).

\section{Meta-analysis of VDR Apal polymorphism and PCOS susceptibility}

The heterogeneity of the 7 selected studies were employed to assess the overall association between the VDR gene ApaI polymorphism and the risk of PCOS. When $\mathrm{I}^{2}>50 \%$, we selected random-effects, and for $\mathrm{I}^{2}<50 \%$ we selected the fixed model. Variant allele genetic model (a compared with A: $\mathrm{p}=0.01 ; \mathrm{OR}=1.2,95 \% \mathrm{CI}=1.04-1.37$ ), additive/homozygous genetic model (aa compared with AA: $\mathrm{p}=0.01$; OR = $1.41,95 \% \mathrm{CI}=1.08-1.84)$ and risk genetic model (aa+Aa compared with AA: $\mathrm{p}=0.01 ; \mathrm{OR}=1.29,95 \% \mathrm{CI}=1.05-1.59$ ) showed the risk of the occurrence of PCOS in response to the VDR gene ApaI polymorphism, whereas the common model (aa compared with AA+Aa: $\mathrm{p}=0.29$; OR $=1.11$, 95\% CI $=0.91-1.36$ ) did not show any risk of PCOS associated with VDR gene ApaI polymorphism (Fig. 2A-D, Table 4).

\section{Subgroup analysis}

Subgroup analysis based on the ethnicity of the study group was performed to detect any relationship between VDR gene ApaI polymorphism and PCOS risk. Then, we conducted a subgroup analysis stratified by population 
(Caucasian vs Asian). In the Asian population, ${ }^{21,22,24,26}$ we found statistically significant increased risk of PCOS in additive or homozygous genetic model (aa compared with AA: $p=0.03$; OR $=1.54,95 \% C I=1.04-2.28$ ) (Fig. $2 B$ ). However, other genetic models, i.e., allele model (a compared with $\mathrm{A}: \mathrm{p}=0.21$; $\mathrm{OR}=1.18,95 \% \mathrm{CI}=0.91-1.54)$, common model (aa compared with AA+Aa: $\mathrm{p}=0.24$; OR $=1.17$, $95 \% \mathrm{CI}=0.90-1.50)$ and risk model (aa+Aa compared with AA: $\mathrm{p}=0.33$; OR $=1.35,95 \% \mathrm{CI}=0.74-2.47$ ) did not show any risk of PCOS associated with $V D R$ gene ApaI polymorphism (Fig. 2A, 2C, 2D). In the Caucasian population, ${ }^{20,23,25}$ we found statistically significant increased risk of PCOS in allele genetic model (a compared with $\mathrm{A}: \mathrm{p}=0.02$; $\mathrm{OR}=1.34,95 \% \mathrm{CI}=1.00-1.79)$ and risk genetic model (aa+Aa compared with AA: $\mathrm{p}=0.03 ; \mathrm{OR}=1.36,95 \% \mathrm{CI}=1.04-1.79$ ) (Fig. 2A, 2D). However, in other genetic models, i.e., additive/homozygous model (aa compared with AA: $\mathrm{p}=0.15$; $\mathrm{OR}=1.31,95 \% \mathrm{CI}=0.91-1.89$ ) and common model (aa compared with $\mathrm{AA}+\mathrm{Aa}: \mathrm{p}=0.83 ; \mathrm{OR}=1.04,95 \% \mathrm{CI}=0.75-1.43$ ) did not show any risk of PCOS associated with $V D R$ gene ApaI polymorphism (Fig. 2B, 2C).

\section{Publication bias}

Funnel plot was carried out to estimate the publication bias among the studies included in this meta-analysis (Fig. 3-6). The emergence of the shape of the funnel plots has not revealed any evidence of publication bias for all the comparison models (a compared with A, aa compared with AA, aa+Aa compared with AA, and aa compared with $\mathrm{Aa}+\mathrm{AA})$.

\section{Discussion}

Lately, genetic susceptibility to PCOS has led to increasing interest in the study of polymorphisms of genes. This has resulted in the investigation of a number of candidate genes as a way to analyze the possible connection between modulations of PCOS risk across various populations. ${ }^{20-27}$ To date, various reports have been published that have evaluated the possible association of $V D R$ gene ApaI polymorphism and PCOS development, but the findings from different studies were inconsistent and contradictory. Hence, pooled analysis with sufficient power was needed to summarize individual studies. In the present meta-analysis, we aimed to obtain summary estimates for the strength

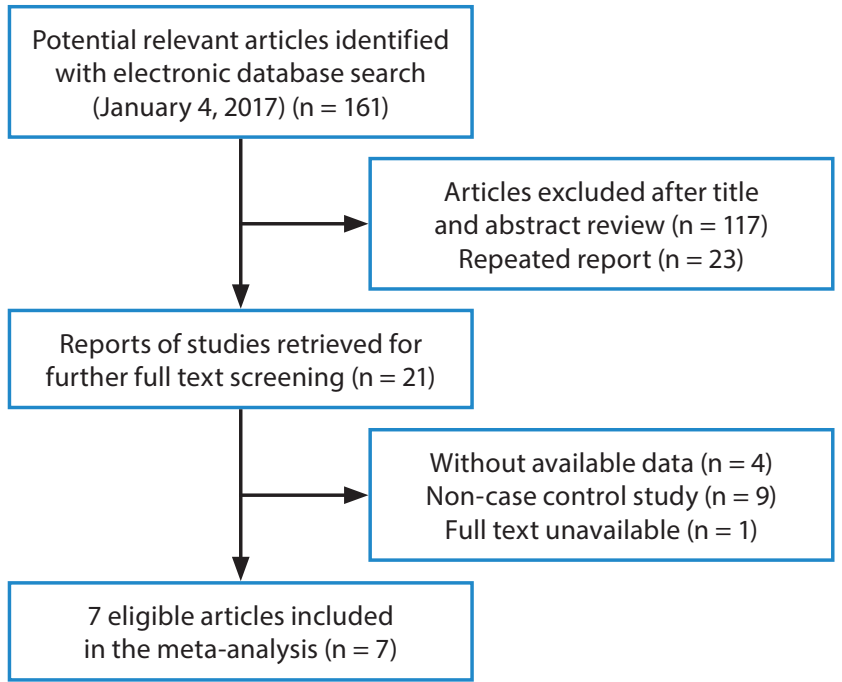

Fig. 1. Results of the literature search strategy

of the association of the VDR gene ApaI polymorphism and PCOS risk from 7 case-control studies, ${ }^{20-26}$ as pooling of the data from individual studies has the advantage of reducing random errors. Also, most of the included studies scored 5 or more stars in NOS quality assessment score criteria and suggested good to moderate quality by clearly stating the sample size, genotype, inclusion criteria of patients, and characteristics of healthy controls.

Our novel findings concerning gene models analysis are the following: the frequency of haplotype ApaI "a" was significantly increased in PCOS women compared to that in the controls, while the additive "aa" and risk "aa+Aa" genotype appeared to confer an increased risk for PCOS. The pathophysiological mechanism of these associations is still unclear. Previously, Mahmoudi et al. also reported a relationship between ApaI polymorphisms and PCOS risk. ${ }^{21} \mathrm{~A}$ previous report by Dasgupta et al. reported that $V D R$ gene polymorphisms have not shown

Table 4. Meta-analysis of VDR gene Apal polymorphism and polycystic ovary syndrome (PCOS) susceptibility

\begin{tabular}{|c|c|c|c|c|c|c|c|c|}
\hline \multirow{2}{*}{$\begin{array}{l}\text { Genetic } \\
\text { model }\end{array}$} & \multirow{2}{*}{ Subgroups } & \multirow{2}{*}{$\begin{array}{l}\text { Number } \\
\text { of studies }\end{array}$} & \multicolumn{2}{|c|}{ Heterogeneity } & \multirow{2}{*}{$\begin{array}{l}\text { Effect } \\
\text { model }\end{array}$} & \multicolumn{3}{|c|}{ Meta-analysis } \\
\hline & & & $\mathrm{I}^{2}[\%]$ & $p$-value & & OR $(95 \% \mathrm{Cl})$ & Z-test & p-value \\
\hline \multirow{3}{*}{$\mathrm{a} / \mathrm{A}$} & total & 7 & 14 & 0.24 & fixed & $1.20(1.04 \sim 1.37)$ & 2.57 & 0.01 \\
\hline & Asians & 4 & 51 & 0.08 & random & $1.18(0.91 \sim 1.54)$ & 1.23 & 0.21 \\
\hline & Caucasians & 3 & 0 & 0.74 & fixed & $1.25(1.04 \sim 1.50)$ & 2.36 & 0.02 \\
\hline \multirow{3}{*}{ aa/AA } & total & 7 & 0 & 0.53 & fixed & $1.41(1.08 \sim 1.84)$ & 2.51 & 0.01 \\
\hline & Asians & 4 & 23 & 0.28 & fixed & $1.54(1.04 \sim 2.28)$ & 2.13 & 0.03 \\
\hline & Caucasians & 3 & 0 & 0.64 & fixed & $1.31(0.91 \sim 1.89)$ & 1.44 & 0.15 \\
\hline \multirow{3}{*}{$a a / A A+A a$} & total & 7 & 14 & 0.32 & fixed & $1.11(0.91 \sim 1.36)$ & 1.05 & 0.29 \\
\hline & Asians & 4 & 46 & 0.14 & fixed & $1.17(0.90 \sim 1.50)$ & 1.17 & 0.24 \\
\hline & Caucasians & 3 & 0 & 0.57 & fixed & $1.04(0.75 \sim 1.43)$ & 0.22 & 0.83 \\
\hline \multirow{3}{*}{$a a+A a / A A$} & total & 7 & 44 & 0.10 & fixed & $1.34(1.00 \sim 1.79)$ & 1.95 & 0.05 \\
\hline & Asians & 4 & 67 & 0.03 & random & $1.35(0.74 \sim 2.47)$ & 0.98 & 0.33 \\
\hline & Caucasians & 3 & 0 & 0.52 & fixed & $1.36(1.04 \sim 1.79)$ & 2.22 & 0.03 \\
\hline
\end{tabular}




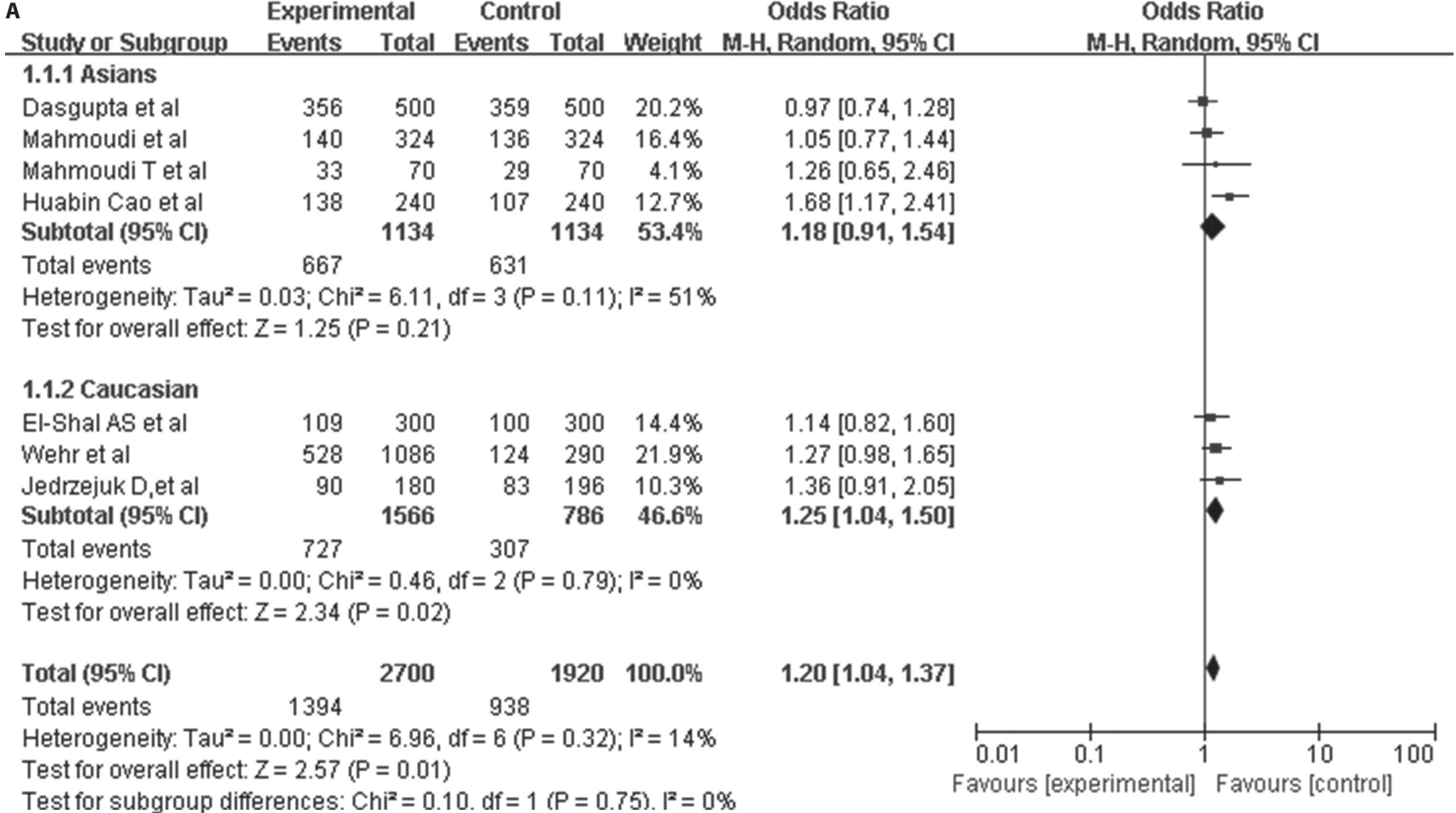

B

Events Total Events Total Weight M-H, Fixed, 95\% Cl

Odds Ratio

\begin{tabular}{lrrrrrr} 
Stucty or Subqroup & Events & Total & Events & Total & Weight & M-H, Fixed, 95\% Cl \\
\hline 4.1.1 Asians & & & & & & \\
Dasgupta et al & 118 & 130 & 121 & 133 & $12.2 \%$ & $0.98[0.42,2.26]$ \\
Huabin Cao et al & 40 & 62 & 26 & 65 & $10.0 \%$ & $2.73[1.33,5.60]$ \\
Mahmoudi et al & 36 & 94 & 23 & 72 & $17.8 \%$ & $1.32[0.69,2.52]$ \\
Mahmoudi T et al & 6 & 14 & 9 & 24 & $4.2 \%$ & $1.25[0.33,4.79]$ \\
Subtotal (95\% Cl) & & $\mathbf{3 0 0}$ & & 294 & $\mathbf{4 4 . 2 \%}$ & $\mathbf{1 . 5 4 [ 1 . 0 4 , 2 . 2 8 ]}$ \\
Total events & 200 & & 179 & & &
\end{tabular}

Heterogeneity: $\mathrm{Chi}^{2}=3.87, \mathrm{df}=3(P=0.28) ; \mathrm{I}^{2}=23 \%$

Test for overall effect: $Z=2.13(P=0.03)$

\subsubsection{Caucasian}

$\begin{array}{lrrrrrr}\text { El-Shal AS et al } & 22 & 85 & 18 & 86 & 14.7 \% & 1.32[0.65,2.69] \\ \text { Jedrzejuk D,et al } & 19 & 38 & 17 & 49 & 8.2 \% & 1.88[0.79,4.48] \\ \text { Wehr et al } & 127 & 269 & 37 & 85 & 32.9 \% & 1.16[0.71,1.90] \\ \text { Subtotal (95\% Cl) } & & \mathbf{3 9 2} & & \mathbf{2 2 0} & \mathbf{5 5 . 8} \% & \mathbf{1 . 3 1}[\mathbf{0 . 9 1 , 1 . 8 9 ]} \\ \text { Total events } & 168 & & 72 & & & \end{array}$

Heterogeneity: $\mathrm{Chi}^{2}=0.91, \mathrm{df}=2(\mathrm{P}=0.64) ; \mathrm{I}^{2}=0 \%$

Test for overall effect: $Z=1.44(P=0.15)$

Total $(95 \% \mathrm{Cl})$

Total events

Heterogeneity: $\mathrm{Chi}^{2}=5.11, \mathrm{df}=6(\mathrm{P}=0.53) ; \mathrm{I}^{2}=0 \%$

Test for overall effect: $Z=2.51(P=0.01)$

Test for subgroup differences: $\mathrm{Chi}^{2}=0.34 . \mathrm{df}=1(\mathrm{P}=0.56) . \mathrm{I}^{2}=0 \%$
$514100.0 \% \quad 1.41[1.08,1.84]$

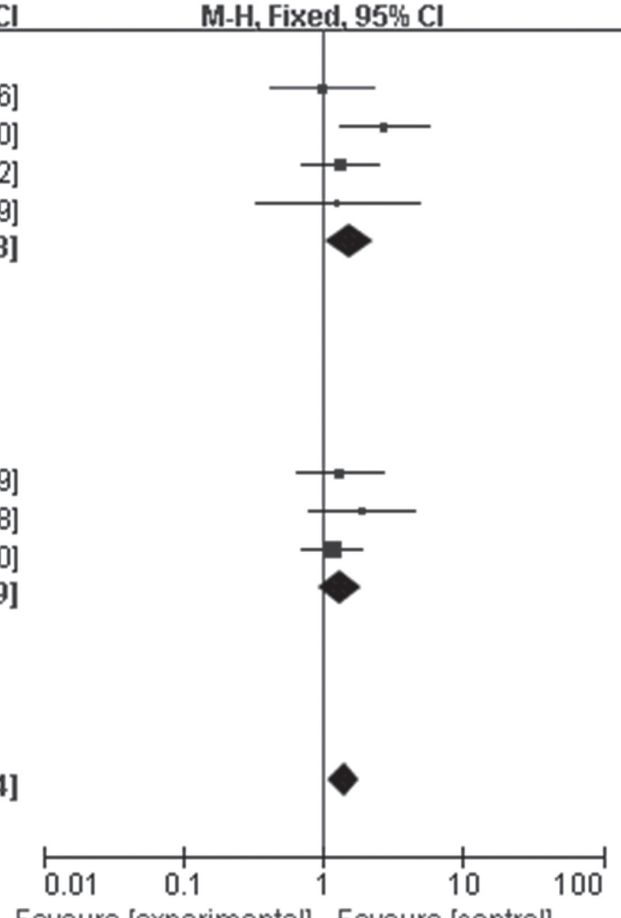

Favours [experimental] Favours [control]

Fig. 2. A - allelic model, B - additive model

a significant association with PCOS, which is inconsistent with several previous independent studies. ${ }^{22}$ Also, they found some contradictory results of increased PCOS risk and suggested that this may have been a result of different experimental designs or methods, and that the issue warranted further investigation. In comparison with previously published reports, the present study has major improvements, as it included only specific PCOS cases of relevant published studies. When we studied the Asian and Caucasian population separately, we found strong evidence that variant additive "aa" confers susceptibility to PCOS in Asians, while haplotype ApaI "a" and risk "aa+Aa" genotype appeared to confer an increased risk for PCOS in Caucasians. This finding may help to explain 


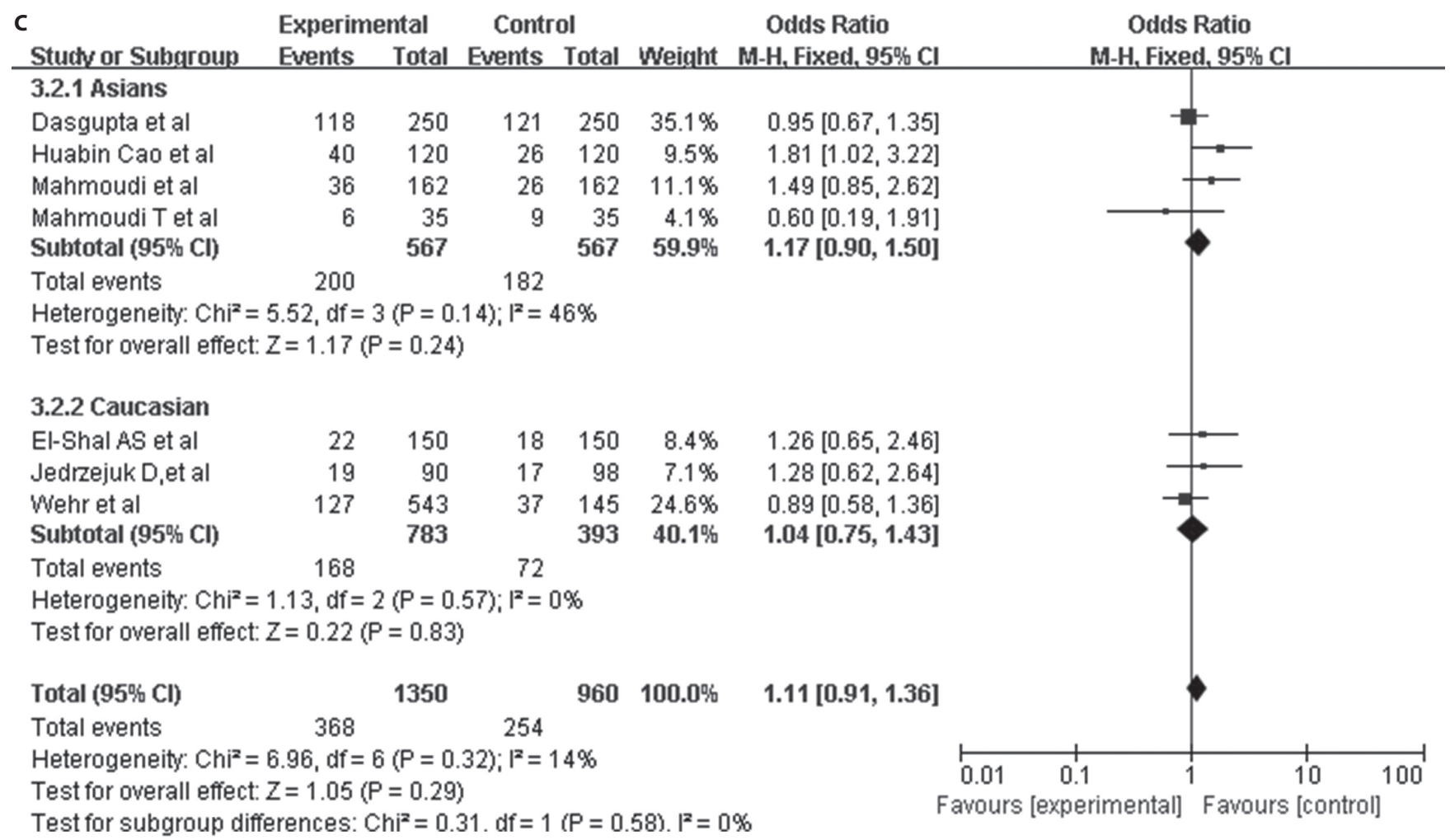

D

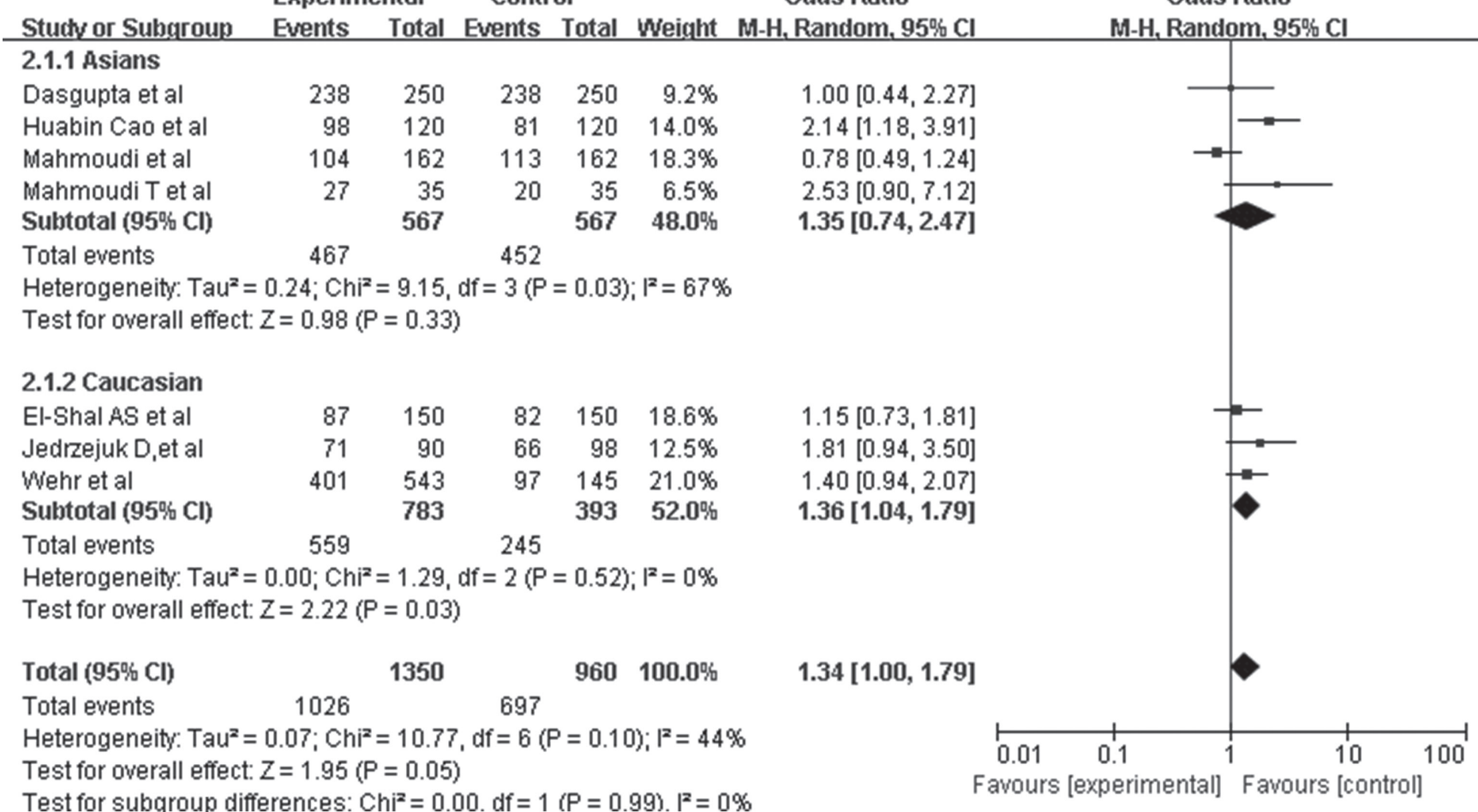

Fig. 2. A - allelic model. B - additive model (cont.)

the individual differences in the susceptibility to PCOS. A study by El-Shal et al. reported that ApaI was associated with a higher PCOS risk more than control genes in Egyptian women. ${ }^{23}$ However, more experimental studies with a larger sample size or alternative methods must be applied for further investigation to verify such findings, as only the mutant genes showed a significant outcome.
As it has been established that PCOS is a complex, multifactorial disease influenced by both environmental and genetic factors, ${ }^{28}$ a single genetic variant is normally insufficient to prevent susceptibility toward this disease. The important feature of this gene polymorphism is that its occurrence can vary sufficiently among different races or ethnic populations. 


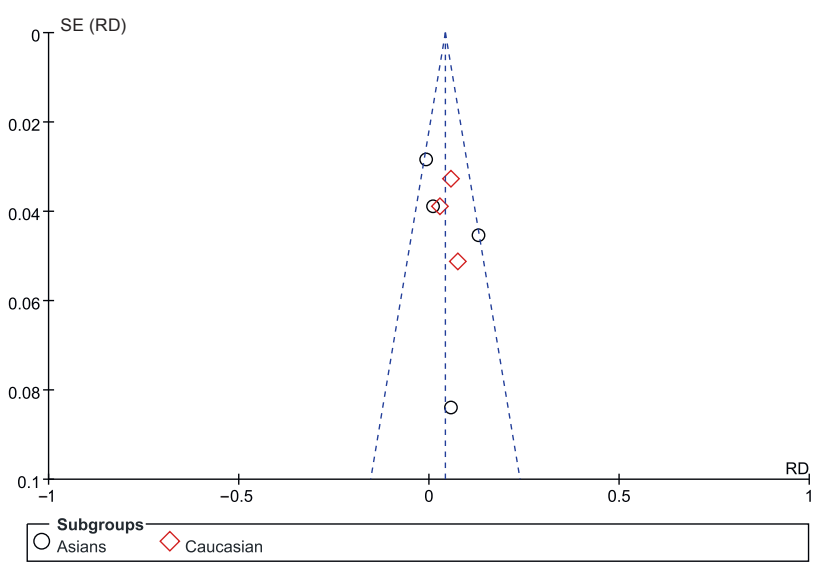

Fig. 3. Publication bias of allelic model

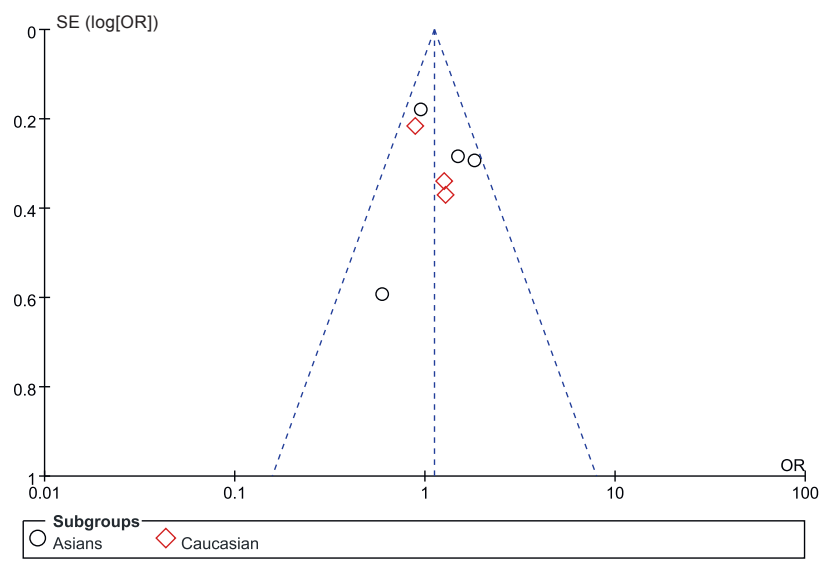

Fig. 4. Publication bias of recessive model

Prior to reaching a final conclusion, limitations of this meta-analysis should also be acknowledged. ${ }^{29-31}$ Firstly, we found significant heterogeneity in the overall analysis. Many factors might have contributed to this heterogeneity, e.g., variation in patients' characteristics might have been an important source of heterogeneity. Some studies used matched controls (e.g., age- and sex-matched), while other studies did not perform matching. Secondly, only reports published in English were considered in the present study. The $3^{\text {rd }}$ and the most important limitation is that the studies searched for in this pooled data analysis were indexed by the selected electronic web-databases (i.e., PubMed, Web of Science, Embase). There is, therefore, a possibility there that some pertinent articles published in other languages and/or indexed in other databases (which are not known to us) may have been missed. The $4^{\text {th }}$ limitation is that since the relevant complete data is not available for most of the time, we failed to adjust the confounding factors, such as age, sex and PCOS severity in this meta-analysis. The $5^{\text {th }}$ constraint was that we were unsuccessful in computing the gene and environmental interactions because of lack of sufficient information in the primary studies.

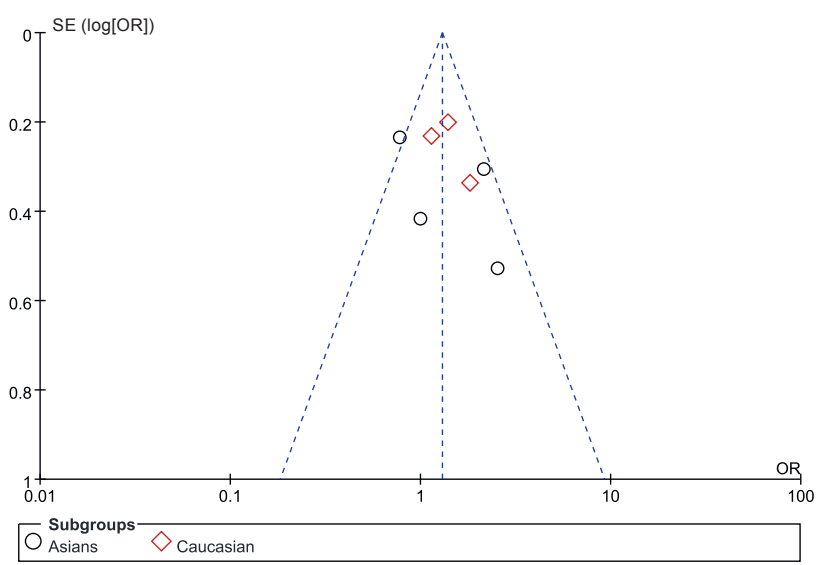

Fig. 5. Publication bias of dominant model

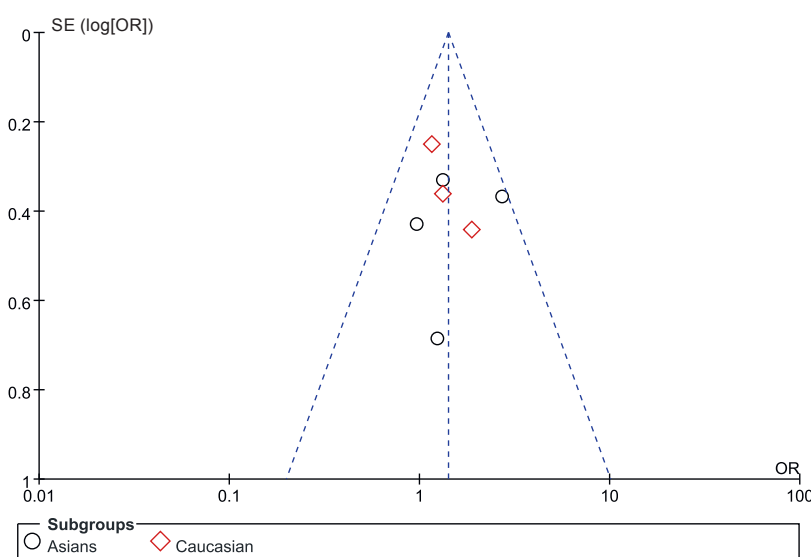

Fig. 6. Publication bias of addictive model

Despite the abovementioned drawbacks, there are some strong points of our meta-analysis that support the reliability of the present results. Firstly, this metaanalysis involved a large set of harmonized individual level data from 7 independent studies, which provided enough statistical power to confirm our results. Secondly, funnel plot indicated no publication bias. Also, all the included studies were of good to modest quality, fulfilling the preset needful criteria as tested by NOS quality assessment scale. Thirdly, although plenty of metaanalyses considering various case-control studies have been performed in the past, we further analyzed the relationship from the point of ethnicity subgroup. ${ }^{32,33}$

In summary, this data suggests that the $V D R$ gene ApaI polymorphism is associated with PCOS. Therefore, $V D R$ gene ApaI polymorphism is considered to be one of the possible factors of PCOS predisposition. Furthermore, it is possible that the VDR gene, at least in part, through its effects on insulin resistance and serum levels of insulin, is involved in the pathology of PCOS. However, further studies are needed to confirm the findings and clarify the biological mechanisms by which the polymorphism influences the PCOS risk. 


\section{Conclusions}

Our meta-analysis demonstrated that PCOS was significantly associated with $V D R$ gene ApaI polymorphism. However, due to the relatively small sample size in this meta-analysis, further studies with a larger sample size should be conducted to confirm the findings.

\section{References}

1. Ranjzad F, Mahban A, Shemirani Al, et al. Influence of gene variants related to calcium homeostasis on biochemical parameters of women with polycystic ovary syndrome. J Assist Reprod Genet. 2011;28(3):225-232.

2. Dunaif A. Insulin resistance and the polycystic ovary syndrome: Mechanism and implications for pathogenesis. Endocr Rev. 1997;18(6):774-800.

3. Diamanti KE, Kouli CR, Bergiele AT, et al. A survey of the polycystic ovary syndrome in the Greek island of Lesbos: Hormonal and metabolic profile. J Clin Endocrinol Metab. 1999;84(11):4006-4011.

4. Asunción M, Calvo RM, San Millán JL, Sancho J, Avila S, Escobar-Morreale HF. A prospective study of the prevalence of the polycystic ovary syndrome in unselected Caucasian women from Spain. J Clin Endocrinol Metab. 2000;85(7):2434-2438.

5. Voulgaris N, Papanastasiou L, Piaditis G, et al. Vitamin D and aspects of female fertility. Hormones (Athens). 2017;16(1):5-21.

6. Okoroh EM, Boulet SL, George MG, Craig Hooper W. Assessing the intersection of cardiovascular disease, venous thromboembolism, and polycystic ovary syndrome. Thromb Res. 2015;136(6):1165-1168.

7. Deligeoroglou E, Karountzos V. Dysfunctional uterine bleeding as an early sign of polycystic ovary syndrome during adolescence: An update. Minerva Ginecol. 2017;69(1):68-74.

8. Gunning MN, Fauser BCJM. Are women with polycystic ovary syndrome at increased cardiovascular disease risk later in life? Climacteric. 2017;20(3):222-227.

9. Shafiee MN, Seedhouse C, Mongan N, et al. Up-regulation of genes involved in the insulin signaling pathway (IGF1, PTEN and IGFBP1) in the endometrium may link polycystic ovarian syndrome and endometrial cancer. Mol Cell Endocrinol. 2016;424:94-101.

10. Condorelli RA, Calogero AE, Di Mauro M, La Vignera S. PCOS and diabetes mellitus: From insulin resistance to altered beta pancreatic function, a link in evolution. Gynecol Endocrinol. 2017;33(9):665-667.

11. Al Nofal A, Viers LD, Javed A. Can the source of hyperandrogenism in adolescents with polycystic ovary syndrome predict metabolic phenotype? Gynecol Endocrinol. 2017;33(11):882-887.

12. Lazúrová I, Figurová J, Lazúrová Z. Diagnostics of polycystic ovary syndrome [in Czech]. Vnitr Lek. 2015;61(Suppl 5):40-44.

13. Gruber BM. The phenomenon of vitamin D [in Polish]. Postepy Hig Med Dosw (Online). 2015;69:127-139.

14. Trochoutsou Al, Kloukina V, Samitas K, Xanthou G. Vitamin-D in the immune system: Genomic and non-genomic actions. Mini Rev Med Chem. 2015;15(11):953-963.

15. Macut D, Bjekić-Macut J, Rahelić D, Doknić M. Insulin and the polycystic ovary syndrome. Diabetes Res Clin Pract. 2017;130:163-170.

16. He C, Lin Z, Robb SW, Ezeamama AE. Serum vitamin D levels and polycystic ovary syndrome: A systematic review and meta-analysis. Nutrients. 2015;7(6):4555-4577.
17. Liu Z, Liu L, Chen X, He W, Yu X. Associations study of vitamin D receptor gene polymorphisms with diabetic microvascular complications: A meta-analysis. Gene. 2014;546(1):6-10.

18. Zadeh-Vakili A, Ramezani Tehrani F, Daneshpour MS, Zarkesh M, Saadat N, Azizi F. Genetic polymorphism of vitamin D receptor gene affects the phenotype of PCOS. Gene. 2013;515(1):193-196.

19. Wehr E, Trummer O, Giuliani A, Gruber HJ, Pieber TR, ObermayerPietsch B. Vitamin D-associated polymorphisms are related to insulin resistance and vitamin D deficiency in polycystic ovary syndrome. Eur J Endocrinol. 2011;164(5):741-749.

20. Jędrzejuk D, Łaczmański $Ł$, Milewicz A, et al. Classic PCOS phenotype is not associated with deficiency of endogenous vitamin $D$ and VDR gene polymorphisms rs731236 (Taql), rs7975232 (Apal), rs1544410 (Bsml), rs10735810 (Fokl): A case-control study of lower Silesian women. Gynecol Endocrinol. 2015;31(12):976-979.

21. Mahmoudi T, Majidzadeh-A K, Farahani $H$, et al. Association of vitamin $D$ receptor gene variants with polycystic ovary syndrome: A case control study. Int J Reprod Biomed (Yazd). 2015;13(12):793-800.

22. Dasgupta S, Dutta J, Annamaneni S, Kudugunti N, Battini MR. Association of vitamin $D$ receptor gene polymorphisms with polycystic ovary syndrome among Indian women. Indian JMed Res. 2015;142(3):276-285.

23. El-Shal AS, Shalaby SM, Aly NM, Abdelaziz AM. Genetic variation in the vitamin $D$ receptor gene and vitamin $D$ serum levels in Egyptian women with polycystic ovary syndrome. Mol Biol Rep. 2013;40(11):6063-6073.

24. Mahmoudi T. Genetic variation in the vitamin D receptor and polycystic ovary syndrome risk. Fertil Steril. 2009;92(4):1381-1383.

25. Wehr E, Trummer O, Giuliani A, Gruber HJ, Pieber TR, ObermayerPietsch B. Vitamin D-associated polymorphisms are related to insulin resistance and vitamin $D$ deficiency in polycystic ovary syndrome. Eur J Endocrinol. 2011;164(5):741-749.

26. Huabin CAO, Ling TU. Association between vitamin D receptor gene polymorphism and polycystic ovary syndrome. Pract Clin Med. 2017;17:40-53.

27. Santos BR, Mascarenhas LP, Satler F, Boguszewski MCS, Spritzer PM. Vitamin $D$ receptor gene polymorphisms and sex steroid secretion in girls with precocious pubarche in southern Brazil: A pilot study. J Endocrinol Invest. 2012;35(8):725-729.

28. Fenichel P, Rougier C, Hieronimus $S$, Chevalier N. Which origin for polycystic ovaries syndrome: Genetic, environmental or both? Ann Endocrinol (Paris). 2017;78(3):176-185.

29. Sahin OA, Goksen D, Ozpinar A, Serdar M, Onay H. Association of vitamin $D$ receptor polymorphisms and type 1 diabetes susceptibility in children: A meta-analysis. Endocr Connect. 2017;6(3):159-171.

30. Wang Q, Xi B, Reilly KH, Liu M, Fu M. Quantitative assessment of the associations between four polymorphisms (Fokl, Apal, Bsml, Taql) of vitamin D receptor gene and risk of diabetes mellitus. $\mathrm{Mol}$ Biol Rep. 2012;39(10):9405-9414.

31. Areeshi MY, Mandal RK, Dar SA, et al. A reappraised meta-analysis of the genetic association between vitamin $D$ receptor Bsml(rs1544410) polymorphism and pulmonary tuberculosis risk. Biosci Rep. 2017;37(3):BSR20170247.

32. Yu M, Chen GQ, Yu F. Lack of association between vitamin D receptor polymorphisms Apal (rs7975232) and Bsml (rs1544410) and osteoporosis among the Han Chinese population: A metaanalysis. Kaohsiung J Med Sci. 2016;32(12):599-606.

33. Liang $F$, Wang $K$, Zhang $H$, et al. Serum 25 -hydroxyvitamin D levels and diabetic retinopathy: A systematic meta-analysis. Int J Clin Exp Pathol. 2016;9(12):12843-12848. 